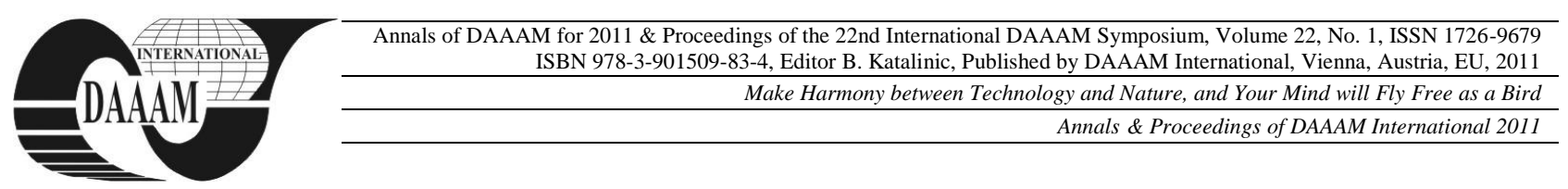

\title{
AN INTEGRATED APPROACH FOR DEVELOPING A CONCEPT FOR A MANUFACTURING EXECUTION MODEL
}

\section{KOKLA, M[arko]}

\begin{abstract}
A different manufacturing concept (Lean, Six Sigma) has been used extensively to improve the results of manufacturing enterprises. Today there is an abundance of literature on many techniques and methods, yet there is very little information on integrating techniques with Manufacturing Execution System (MES) and its impact on various industries. This article describes the results of a stage in a case study aimed at establishing an expert system for developing integrated Manufacturing Execution Systems. The model concept can be used to develop the fields of Intelligent Production Planning, Monitoring and Diagnosis, which are part of Intelligent Manufacturing Technology (IMT).
\end{abstract}

Key words: manufacturing, intelligent manufacturing system, lean

\section{INTRODUCTION}

Manufacturing has been the basic foundation of the economy and the living environment from the Industrial Revolution to the information era. Manufacturing organizations face a major challenge: developing a manufacturing system and creating an environment in which people are able to practice self-management. In this century, serious pressure has been brought to bear on society in the field of intelligence - increase in competition, globalization, sustainability of production and many other aspects such as the economic downturn and downward pressure on manufacturing costs. One possibility is to improve management systems (including the manufacturing control system) in order to reduce costs. Above all, this means organizations with lower management structure and a smaller number of managers (Nasarwanji et al., 2009). In this context, there is a need to simplify managerial decisions and make the manufacturing system function more effective.

The goal of this study was to find a possible model concept of integrated instruments and methods on the basis of which it would be possible to create a MES for developing manufacturing control in an e-manufacturing environment.

\section{MES MODEL CONCEPT REFERENCE SYSTEM}

There are two key factors in the field of intelligent manufacturing (the IT field) (Zhou et al., 2010):

1. Intelligent Production Planning

2. Intelligent Monitoring and Diagnosis

From the standpoint of manufacturing control, standardized information technology solutions have not yet been sufficiently integrated on the basis of methods and instruments that are used in manufacturing (see section 3).

Use of MES systems has been on the increase only in the last ten years and in the direction of reduced operating costs and greater automation of decisions. MES can be divided into three function groups (Kletti 2007): The functionalities for production, quality and personnel allocation.

The efficient development of a manufacturing enterprise depends largely on the manufacturing system and the development of the expert system depends on the design of the production system and flexible design (Jovane et al., 2010). In this study, the Lean concept instruments and methods (Womack \& Jones, 2003) will be of assistance in developing the production system.

The basis for developing the concept for the current model is testing integrated Lean concept and developing a structure for the concept of the MES model. The creation of the model is due to the rapid and efficient development through the information technology management system.

\section{RESEARCH METHODS AND APPLICATIONS USED}

The study was conducted in the framework of the first stage of the e-manufacturing concept:

1. Creation of the model concept for developing the management system (MES) for the SME manufacturing enterprise's e-platform (described in the article).

2. Finding applications, testing functionality in other companies, adjustments and assessments and documenting the model and applications.

An empirical case study was used as a study method, in the course of which observations, data processing and analysis were conducted. On the basis of the results obtained, a management system concept for developing MES was modelled. Based on the case study conducted, the most important factors for efficient development of manufacturing system (principles, instruments and methods) were identified:

- Methods as Kanban, 5-S

- Product families matrix

- Optimum material flow matrix and schematic

- Current \& Future value stream map

- Technology and skills matrix

The basis for measuring the efficiency of the manufacturing system is the Lean concept instrument Total Productive Maintenance (TPM) method Overall Equipment Effectiveness (OEE). The results of key indicators accompanying the OEE method show the performance of the said concept. The second key instrument is implementing Kanban in the manufacturing area. In the course of the given study, the launch of the 5-S (work-related organization) project took place in addition to the visual Kanban.

\section{MES MODEL CONCEPT}

MES gives a company an advantage in planning manufacturing and transmission of information on the operational level; in addition the system independently promotes growth in productivity and quality. The independent capacity of the system for growth in productivity results in a more intelligent manufacturing system. The same is argued by Sousa \& Ramos, 1999 (Zhou et al., 2010): "IMS differs from a conventional manufacturing system - even an advanced one - 
in its inherent capability to adapt to changes without external intervention."

Even so, intelligence is not determined by the components of the system but rather how they are integrated with each other. In 1989, Professor H. Yoshikawa (University of Tokyo) defined an Intelligent Manufacturing System or IMS as " $a$ system which improves productivity by systematizing the intellectual aspect involved in manufacturing, flexibly integrating the entire range of corporate activities, production, and marketing (...) so as to foster the optimum in the relationship between men and intelligent machine" (Zhou et al., 2010).

A concept for the MES system model (Fig. 1) was developed from the applications and factors, integrated with Lean concept instruments consisting of various layers.

\begin{tabular}{|c|}
\hline MES EXPERT SYSTEM MODEL: \\
\hline 1. SELECTION OF MANUFACTURING CONCEPT \\
\hline 2. DESIGN OF MANUFACTURING SYSTEM \\
\hline 3. DETERMINING MANUFACTURING METHOD \\
\hline 4. ANALYSIS OF PRODUCT FAMILIES \\
\hline 5. PRODUCT AND MODEL ANALYSIS \\
\hline 6. BUILDING THE STRUCTURE \\
\hline 7. DESCRIPTION OF RESOURCES \\
\hline 8. SELECTION OF DIMENSIONS \\
9. SYSTEM INTEGRATION \\
\hline
\end{tabular}

Fig. 1. MES model concept

The MES expert system model concept consists of the following system development sequence and aspects:

1. Selection of manufacturing concept. For example: LEAN (principle being eliminating waste), SIX SIGMA (principle being statistical quality control), TQM (principle being total quality control). Activities determining principle and levels.

2. Designing the manufacturing system. Concept methods, for instance: Kanban, Mapping the value stream, Cellular manufacturing. Activity: determining instruments, goals and methods to be used.

3. Determining means of production. For example: Projectbased approach, manufacturing using standard product, Mass production. Activity: determining manufacturing method.

4. Analysis of product families. Description of products and operations. Activity: clustering.

5. Product \& model analysis. Assembling material flow and schematic. Activity: determining when the model becomes product.

6. Building the structure. Preparing value stream maps (current and future). Activity: pursuant to concept, manufacturing system and method, sequence of families and product/model manufacturing process, description of information and material flow. Principles of group technology and consolidated structure (product families).

7. Description of resources. Preparing competences and technology matrix. Activity: description of the technology, determining capabilities, determining cycle times.

8. Selection of dimensions. Activity: the temporal dimension of planning is determined, e.g. predictions; "Master plan"; report interval, archival etc.

9. System integration. Activity: the necessary activities are determined along with integration with other systems, access, etc.

\section{CONCLUSIONS}

As a result of the study, a model conception was created (Fig. 1) of integrated instruments and methods on the basis of which it would be possible to create a MES for developing manufacturing control in an e-manufacturing environment. This model has been implemented for developing MES in the eenvironment, and the first test results show that manufacturing control has become significantly more efficient, as seen in the growth of productivity and decrease in working time spent on administrative management.

During the study period, the growth in effectiveness was $69 \%$. Improvement (I) was calculated using the following formula (1), where the previous state effectiveness is $52 \%$ and new state effectiveness is $88 \%$ :

$$
I=\frac{88 \%-52 \%}{52}=69 \%
$$

In the case of the model concept developed as a result of the study, key factors and instruments are applied in integrated fashion. The model concept modelled as a result of the study is the key for the structure of the MES system and creation of expert systems. In the course of the case study described, these factors showed clear development in the manufacturing enterprise; this development was based on the selected instruments and integration of these instruments.

In the case of a unified model, it would be possible to carry out a more comprehensive transformation of knowledge (including skills) into the manufacturing enterprise. The author calls the implementation of this method the "golden sphere" idea, i.e. unawares to the company, pursuant to the expert system in manufacturing, rapid productivity growth and/or development as a whole will take place in manufacturing. This study does not deal with broader integration of expert systems of enterprises that have a special typology. In the case of this study the model concept should be considered to have been tested in the case of the given manufacturing method. The applications for various manufacturing methods should be tested first.

\section{ACKNOWLEDGEMENTS}

This research was supported by Innovative Manufacturing Engineering Systems Competence Centre IMECC, co-financed by Enterprise Estonia (EAS) and European Union Regional Development Fund (project EU30006).

\section{REFERENCES}

Jovane, F.; Westkämper, E. \& Williams, D. (2010). The ManuFuture Road, Springer/Verlag Berlin Heidelberg, ISBN 978-3-642-09573-3

Kletti, J. (2007). Manufacturing Execution System - MES, Springer Science and Business Media, ISBN 978-3-64208064-7

Nasarwanji, A.; Pearce, D.; Khoudian, P. \& Worcester, R. (2009). The Impact of Manufacturing Execution Systems on Labor Overheads, Proceedings of the World Congress on Engineering 2009 Vol I, 1-3 July 2009, London, UK, ISBN: 978-988-17012-5-1, IAENG

***Zhou, Z.; Wang, H. \& Lou, P. (2010). Manufacturing Intelligence for Industrial Engineering: Methods for System Self-Organization, Learning, and Adaptation, IGI Global, ISBN 978-1-60566-864-2, United States of America

***Womack, J. \& Jones, D. (2003). Lean Thinking, Simon \& Schuster, ISBN 0-7432-3164-3, U.K 